\title{
Systems thinking in designing automotive textiles
}

\author{
Pammi Sinha*, Subramanian Senthilkannan Muthu, lain Taylor, Rita Schulze, Katharine Beverley, Claire Day \\ and Nicoleta Tipi
}

\begin{abstract}
We present the complexities in terms of designing automotive exterior seating materials (seat coverings and interior linings) at Sage Automotive Interiors (UK), which is a division of a global international automotive textile supplier with headquarters in the US. Sustainability and innovation are emphasized in documents communicating the company's vision. Using a case study approach, we consider the current design, development and manufacture process and examine it for the potential for feedback loops, identify potential leverage points to effect change and how the process could divert wastes from disposal. We will highlight where sustainable decisions can be incorporated and the difficulties in achieving true sustainability. We argue that a systems approach is needed from conception to final product to ensure economic recycling of textiles and fibres used in automotive seating. Without which, the reality is at best incineration for energy and/or landfill, thus losing important, finite resources forever from a diminishing resource pool of raw materials.
\end{abstract}

Keywords: Automotive textiles; Sustainability; Systems; Recycling; Incineration; Waste; Landfill

\section{Background}

\section{Systems thinking}

Systems may be defined as a set of independent but interlinked phenomena; identifying and using beneficial relationships and linkages between different parts of a system is key to optimizing the whole (Charnley et al. 2011; Mingers and White 2010). Meadows (1997) identified nine places of intervention to influence and change systems: (9) numbers - subsidies, taxes and standards, (8) material stocks and flows - substituting with more sustainable material, (7) regulating negative feedback loops - control undesirable factors by legislating to minimize harmful materials or processes, e.g. REACH, (6) driving positive feedback loops - encourage desirable factors through promotion and aid for sustainable practices, (5) information flows - working towards transparency in the supply chain, (4) rules of the system - develop existing or new practices and policies beneficial to all stakeholders, (3) the power of self-organization - internal intervention akin to organizational or self-learning, (2) the goals of the system - profit to survive and compete, but now incorporate social and environmental concerns, and (1) the mindset or paradigm out of which the system

\footnotetext{
* Correspondence: p.k.sinha@leeds.ac.uk

Sinha, Beverley, Day, Schultz: Department of Fashion and Textiles,University of Huddersfield, Queensgate, Huddersfield HD1 3DH, UK
}

arises - the accepted status quo, influencing this can bring about the biggest changes. All systems have inputs, outputs and feedback mechanisms; for this paper, we examine the design process for automotive textiles and the system within which it operates in to outline the implications for environmental product design.

\section{Sustainability in the automotive industry}

The European Union's end-of-life vehicles (ELV) directive stipulates that, by $2015,95 \%$ of new vehicles need to be recyclable (EURAPA 2010) and that 'vehicle manufacturers and material and equipment manufacturers must: (a) endeavour to reduce the use of hazardous substances when designing vehicles, (b) design and produce vehicles which facilitate the dismantling, reuse, recovery and recycling of end-of-life vehicles, (c) increase the use of recycled materials in vehicle manufacture and (d) ensure that components of vehicles placed on the market after 1 July 2003 do not contain mercury, hexavalent chromium, cadmium or lead, except in the applications listed in Annex II of the Directive (Normand 2008). Manufacturers are requesting textiles that disassemble and are recyclable; suppliers are being requested to recall their products after use to recycle them (Normand 2008), potentially forcing readjusting their operations to support this new additional element to their business. Many original equipment manufacturers (OEMs) 
currently use the design for disassembly processes using compatible chemicals, components and similar fibre types to increase their recycling and reuse efficiencies. The automotive industry is interesting because environmental sustainability of textiles is not (yet) the main focus of the car companies' sustainability efforts, which centre on fuel efficiency and lightweight cars. OEMs are therefore much more hesitant to make improvements regarding EPD for those 'peripheral' parts of the car which customers are less likely to ask about and where the influence on sales and reputation is perceived as uncertain. On the other hand, seating textiles are visible to the customer, and so, it is important to understand the internal and external pressures which the design team faces. Therefore, the design process is analysed to get a detailed understanding of the factors driving the design decisions.

\section{The automotive assembly system}

Often described as tiered, up to four tiers excluding the OEMs, tier 1 supplies interior compartments, e.g. seats, engines, floors; tier 2 carries out subassembly activities such as cut and sew and supply parts such as headliners; tier 3 supplies the manufacturing for the upholstery whilst tier 4 supplies the materials (Shishoo 2008). Tiers 1 and 2 companies may be integrated, and 'cut and sew' operations may be carried out by the same company. Fabric laminators supply their services the cut and sew operations (Tier 2). The fabric formation companies may also conduct fabric lamination in-house or outsource. There are many permutations; companies may supply yarn directly to the fabric formation company, foam and scrim directly to a fabric lamination company or only yarn to the fabric formation company and the fabric formation company supplies the scrim to the fabric lamination company. Moreover, the three companies may be integrated (Taylor 2012). An example is the consolidation by tier 1 companies. The OEMs, frustrated by the increasingly longer lead times and operational constraints, only worked with fabric suppliers with cut and sew operations. Tier 1 companies (e.g. Johnson Controls) have bought out fabric companies and become vertically integrated companies with control of upstream and downstream activities making the full range of products from seats, instrument panels, headliners, etc. With $25 \%$ of the market, Johnson Controls vertical integration captures increasing amount of value along the chain but loses flexibility and speed. The independent status of Sage AI is advantageous because it affords flexibility and speed within the system (Taylor 2012).

\section{Methods}

A single case study, according to Yin (2009), was conducted using a number of semi-structured interviews from November 2011 until July 2014 (on site and off site), with the managing director, design and development director, designers and members of the logistics and technical team. The interviews were recorded, transcribed and triangulated with the company's documents and literature regarding product development process. The analysis was validated by the design and development director. The commercial sensitivity, the detailed nature of the analysis and associated time requirements necessitated a single case study. Sage AI (UK) was chosen as a case study company due to their strong interest in environmental product development and existing close working relationships with the University.

To analyse the design process, we used Integration Definition for Function (IDEF) modelling, a standardized and widely used method to model manufacturing processes (Rashid and Ismail 2007). Used as a visual tool, it helps describe, analyse and communicate ideas ( $\mathrm{Yu}$ and Wright 1997). It has proven effective for detailed system analysis (Knowledge Based Systems 2010). The modelling often starts from a description of the process at the highest level, which is then broken down hierarchically to the level of detail required for a meaningful analysis. This allows the user to describe the details of complex processes whilst keeping a good overview of the activities (Sugiyama et al. 2008).

IDEF-0 has also been used in the past to support corporate decision-making processes and to support the redesign for the improvement of processes (Hernandez-Matias et al. 2008). In recent years, IDEF-0 has been used to help introduce environmental criteria into business processes. For example, IDEF-0 models were used to illustrate new process designs, considering environmental and health criteria (Hirao et al. 2008) or to show how risk assessment and life cycle assessment can be facilitated using IDEF-0 to help understand the process and information requirements (Kikuchi and Hirao 2009). Kikuchi et al. (2012) used IDEF-0 to illustrate a systematic assessment process for environmental, health and safety aspects in the process development phase. Sugiyama et al. (2008) used IDEF-0 as a modelling tool to support the integration of LCA in process design - the method helped them to highlight information requirements for the newly required activities.

According to the IDEF-0 standard, the purpose and viewpoint, system boundaries and meaning of the arrows should be defined. For this study, the purpose of the model was to understand the design development process of the case study company and to identify where environmentally relevant decisions are made in this process. The model takes the perspective of the design and development director, with the intention to focus on the steps in the design and product development process stages. As a consequence, the model includes all processes which the design team are directly involved in, starting with research and development, design concept development and 
selection by client, up to the point where a master sample of the fabric has been selected as a template for production. Figure 1 demonstrates a basic structure of the IDEF0 (National Institute of Standards and Technology 1993; Kikuchi et al. 2012). The control arrows in the IDEF-0 model represent factors which need to be taken into account in the respective process step. They are the most relevant factors for the identification of the barriers.

The purpose of the IDEF-0 modelling was to obtain a detailed examination of the product design/development process at the case study company and was used as a basis to identify the following:

1) where in the design process the most environmentally relevant decisions are being made

2) the crucial factors affecting these decisions, and

3) barriers to and enablers for environmental product development in the current design process, using the introduction of recycled yarn as a particular case study example.

\section{Results and discussion}

\section{Sage AI (UK) company background}

Sage AI, originally a part of the former Milliken Automotive and the Viktor Achter Groups. Sage Automotive Interiors (Sage AI) business is headquartered in the US, and solely in the automotive sector with bases in Poland, Japan, India, South America and China. The Sage AI business is entirely related to the automotive industry. Their fundamental business is design, incorporating engineered and technical qualities to add value to their products. Sustainability and innovation is paramount to their vision.
Sage AI produces textile interiors based on two manufacturing routes: woven or knitted. Most developments are related to enhancing these processes, e.g. through embossing, stitch and HF welding. The samples are developed through their plants overseas; thus, knowledge of their capabilities is essential. This knowledge accrues through experience, and the creative or technical designers visit the partner manufactures every month. Most innovations are for enhancing the fabrics, e.g. rotary embossing, 12 head embroidery machine and HF welding. Various OEMs now produce shorter runs and offer special editions to add more interest to the colour and design of the automotive Powell NB (2006). The use of embroidery is a new technical capability, enabling mass customization service. When developing initial ideas (for either internal or external clients), Sage AI liaise with their suppliers' technicians to establish feasibility with partner companies; where, if it is not possible, they will develop new supplier relationships and run feasibility trials.

Sage AI (UK) own manufacturing plants in Poland (weave) and Egypt (knit). The creative or technical designers visit the manufacturers monthly to maintain communication and address any design/production issues. Costs limit fibre choice usually to polyester which is then designed for variety of looks, e.g. highly lustrous, soft matt, textured and novelty yarns to create interest in the woven and knitted fabrics. Wool can be used but is expensive, therefore limited (Sage used wool for the BMWi3). Yarns are supplied by Autofil Worldwide Ltd., who also piece- or yarn-dye and texturize to a very wide variety of looks and feel; the blend, has to be visually appealing to the customer (the OEM), pass various

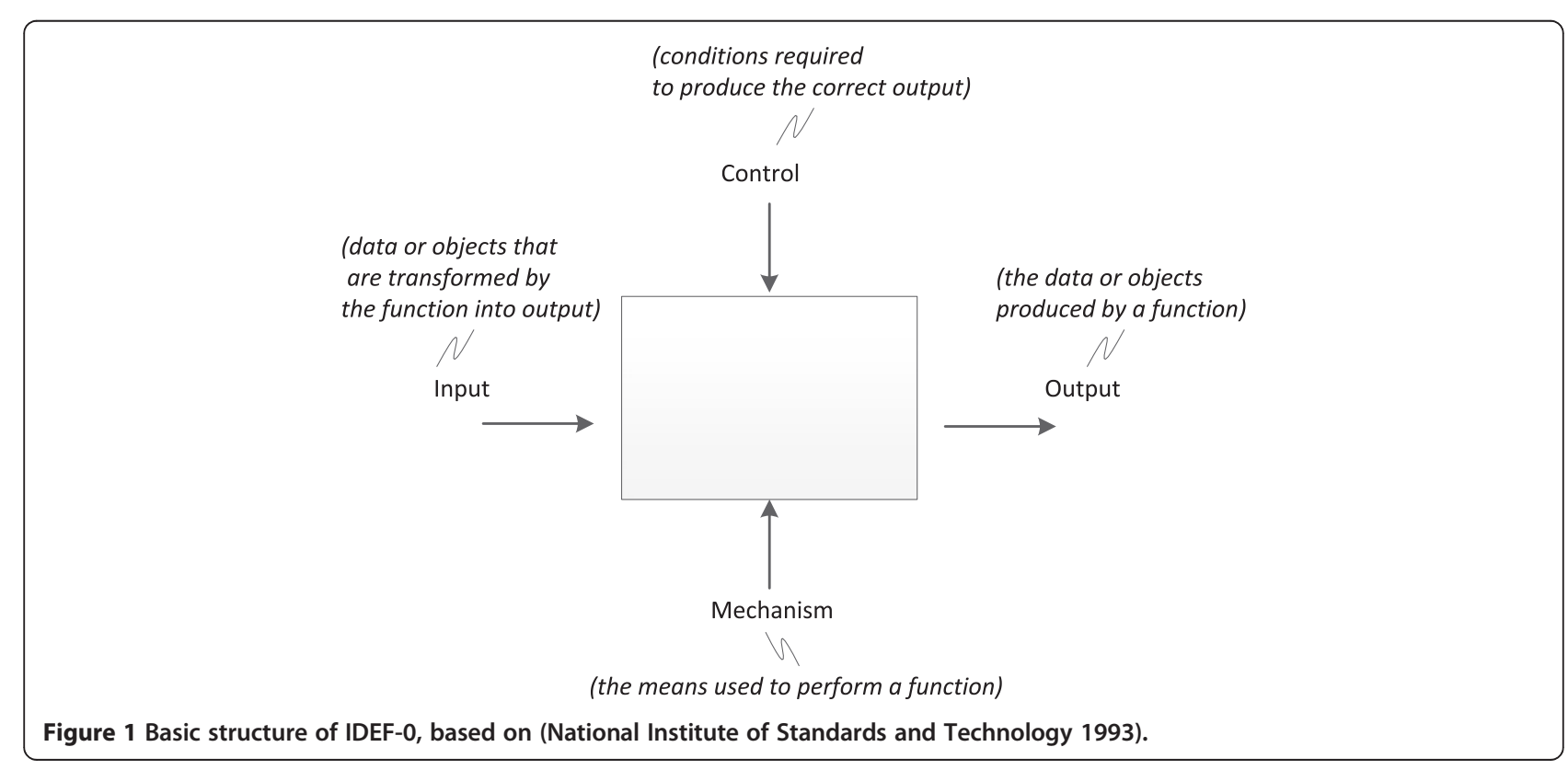


rigorous tests (such as abrasion and light fastness), be durable (up to 10 years) and most importantly, cost effective.

\section{Application of textiles to seating}

The manufactured polyester fabrics are usually laminated with foam and a lightweight fabric 'scrim'. These are manufactured to a schedule and then shipped to a cut and sew company. These companies, often part of the final seat manufacturer, receive the fabric in roll form and mechanically cut parts which are then sewn together to create a seat cover. The covers are then usually shipped, often over long distances, to where the seat itself is being made, where they are incorporated into the final seat. The seat is then sequenced in trackside as the car they are destined for is being made just in time; the seat assembler receives notification of which type, colour and style manufacture of the seat is required a few hours before it is required to meet the rest of the car on the assembly line. Other parts, e.g., engines, headliners, instrument panels, doors etc. are equally sequenced in.

\section{The design and product development process}

The product development process may take between 3 and 5 years from brief setting to final vehicle production. This is extended by the additional 7 years approximate length of time that the textiles will be in vehicle. Figure 2 outlines the process from concept to master sample; for ease of describing the process, stages have been assigned various developmental stages of the process (stages A1 to A4).

Product development or innovation begins with a brief, either from the customer/client (OEM, which designers interviewed termed as client based) or in-house through their own product/consumer knowledge (e.g. designer, manager, etc. - the designers interviewed termed this as open-line brief). Sage AI developed FXC for Honda from a brief set by Honda, whereas YES Essentials was developed through an open-line brief based on internal knowledge and consumer research. It is not uncommon for the OEMs to tender briefs to more than one supplier at a time. OEMs distribute requirements via a brief to specify requirements in terms of objectives for the textiles; this process may commence up to 3 to 5 years in advance of the final vehicle production dependent on whether incremental or innovative design is involved. Dependent on the client's requirements, the brief may focus on pattern requirements and technological developments, whilst others may be more responsive to emotive desires of the consumer (Figure 3a,b).

It may be noted that an extra consideration needs to take place when developing a concept by open-line brief, in that the technical feasibilities and standards for the concept need to be researched; moreover, internal briefs are no longer common at Sage as the resource implications and risks to approval by a potential client are high and raise too many complex questions when considering how copyright is assigned and to whom (Sage or their client).

\section{Stage A1: plan and conduct research and development}

This initial stage A1 can take between 2 weeks and 2 months dependent on the client's needs. According to Powell, a brief will consist of performance [standards] and cost parameters, colour, pattern, scale of pattern, lustre and handle which is then taken forward by the designers (Powell 2008a). Timing and major stage-gates will also be confirmed. If the initial stage-gate is short, the design team will show concepts already in situ to support quick turnaround of sampling; when the stage-gate is long, the designers will develop new concepts for a particular brief, and this may include two stages prior to sampling.

Vehicle interiors are mainly plain, striped, checked or small-scale ditsies in neutral colouring with the addition of a small percentage of a brighter accent colour to add interest (Powell 2008a). Various OEMs who produce shorter runs have started to offer special editions to add more interest into the colour and design of the automotive (Powell et al. 2008b citing Powell 2006). As already stated, vehicles are developed up to 5 years in advance; alongside this is the timeframe of 7 years that the textiles will be in vehicle production before an updated model is developed and ultimately replaces it. Thus, the fabric has to remain on trend for a much lengthier amount of time than fashion or home interiors in terms of appearance and colour.

Due to the long lead times, a global macro-trends study is projected every 4 years and micro-trends analysed such as 'luxury', 'sports' and 'comfort' to focus the design team. Sage AI used to profile geographically but now references according to age and lifestyle, e.g. 'youth' and 'active'. Other elements to be considered are environmental trends, colour, texture and consumer profile. The designers produce a global colour show consisting of four themes to maintain constant fabric design and development and visit trade shows to keep abreast of latest yarn or fabric development techniques and suppliers. Figure 4a illustrates the open-line brief route whilst $4 \mathrm{~b}$ illustrates the OEM set route.

The development of an internal brief provides an opportunity for Sage to develop environmentally friendly innovations. Whether those are taken up by the car manufacturers depends on trends and politics, company strategies and product cost. The risks of the product being accepted are high at this stage; therefore, it is important for Sage to research trends, politics, potential clients' company strategies and estimate the product's cost and feasibility; all of this is resource intensive. 


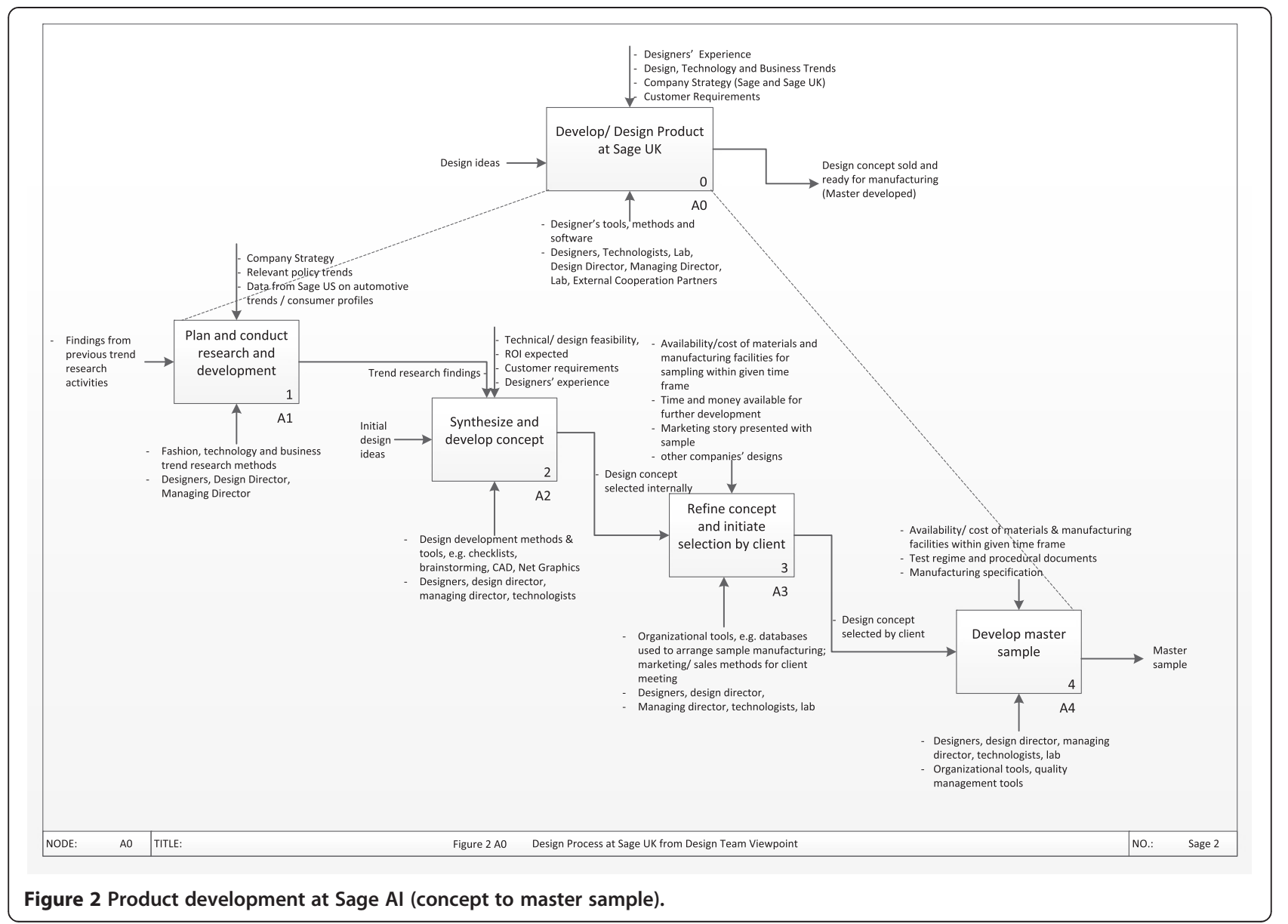

\section{Stage A2: synthesis and development of concept}

The initial idea is transferred into a CAD software. Figure $4 c$ illustrates that the open-line brief route requires an examination of the return on investment of resources spent on developing the concept and its fit with the company's strategic priorities before they proceed to developing it into design ideas for the client.

During stage A2, the design idea is developed into a concept (that will be discussed at a meeting with potential clients). At stage A24, the design idea is examined for selection with regard to whether to continue to refine or not. The design ideas might not be good enough (in which case, they need to go back one step). A design functional modes and effects analysis (dFMEA) review is undertaken which outlines the technical requirements (included in dFMEA) to narrow down the selection of potential fabrics and material; much of this depends on the design team's knowledge of what is likely to work. Technological requirements are manufacturer dependent. Figure 4d illustrates the activities surrounding the decision to select the design concept to develop further.

At stage A25, the concept is refined towards developing a sample. The design concept (perhaps in the form of a CAD illustration, or a selection of archive samples), includes specification of materials, technologies required for the making, sources of laminators, etc.

Figure $4 \mathrm{e}$ illustrates the activities involved in refining the idea into a concept that will be developed for discussion in a client meeting. The concept is produced on a CAD programme (in this case, NED Graphics); this is emailed to the specified manufacturing location and processors and (dependent on colourways) will take 4 to 6 weeks for sampling to materialize. If the colour of the yarn is already available (e.g. black), this would be a 4week process; however, if the yarn needs to be dyed specifically to match other elements of the interior such as vinyls and leathers, this can take approximately 6 weeks.

\section{Stage A3: refine concept and initiate selection by client}

Concepts considered feasible for client discussions are developed into a sample representative of the actual fabric that may be used by the client company (Figure 5a).

Samples to be considered may be new samples designed or they may be archival samples or samples that did not quite achieve the appropriate standards in a 

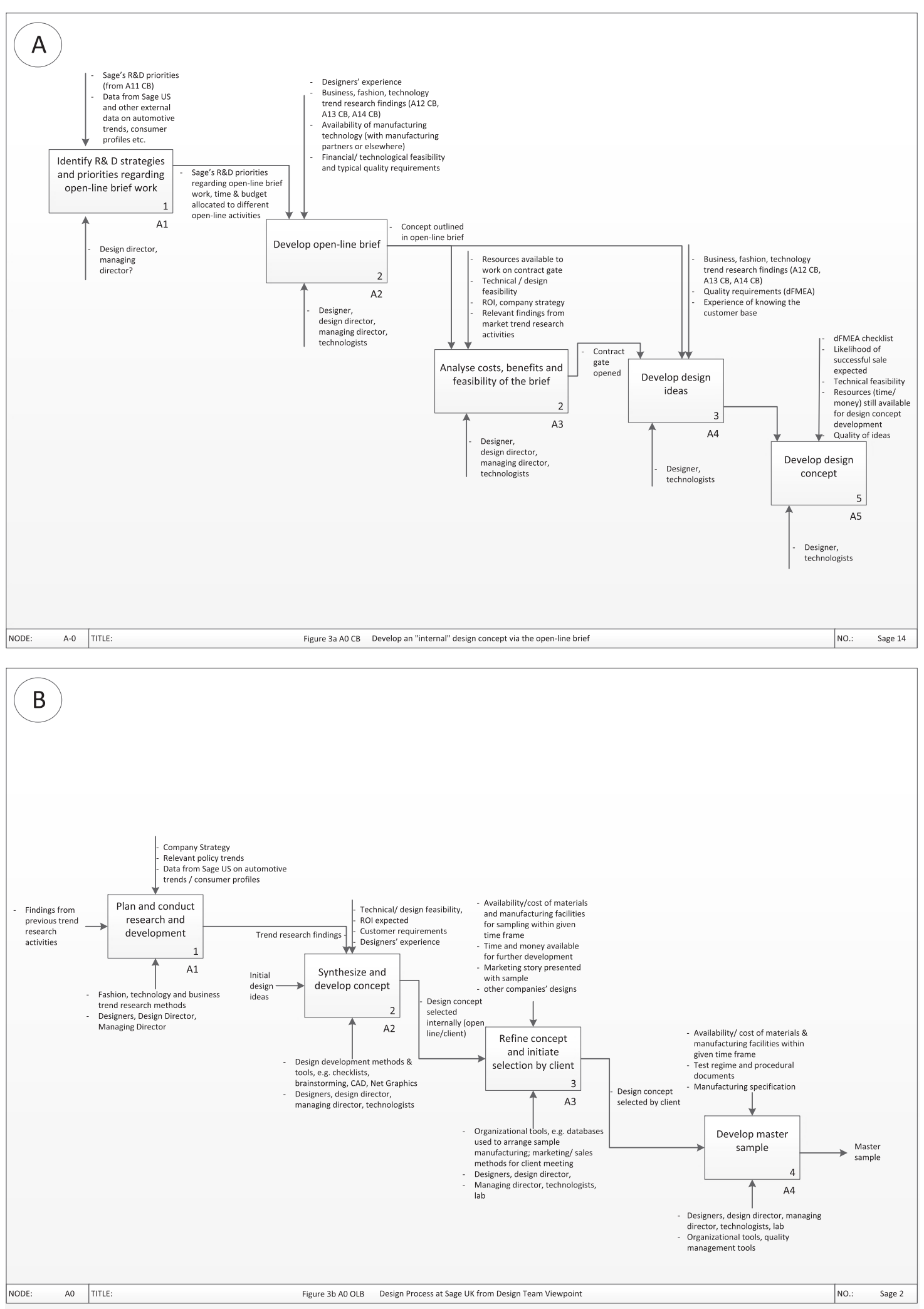

Figure 3 Open-line brief. (A) Open-line brief product development. (B) OEM set brief product development. 




previous round of testing. The overriding considerations are return on investment (likelihood to get the job, likelihood to get good money out of job if accepted), availability of machinery and raw material within specified time frame, time availability and cost of sampling. The initial decision-making regarding whether a sample should be put into manufacture is illustrated in Figure 5b.

Once the decision is made to take a concept to the manufacturing level, specifications for manufacturing need to be developed and defined, as illustrated in Figure 5c. 

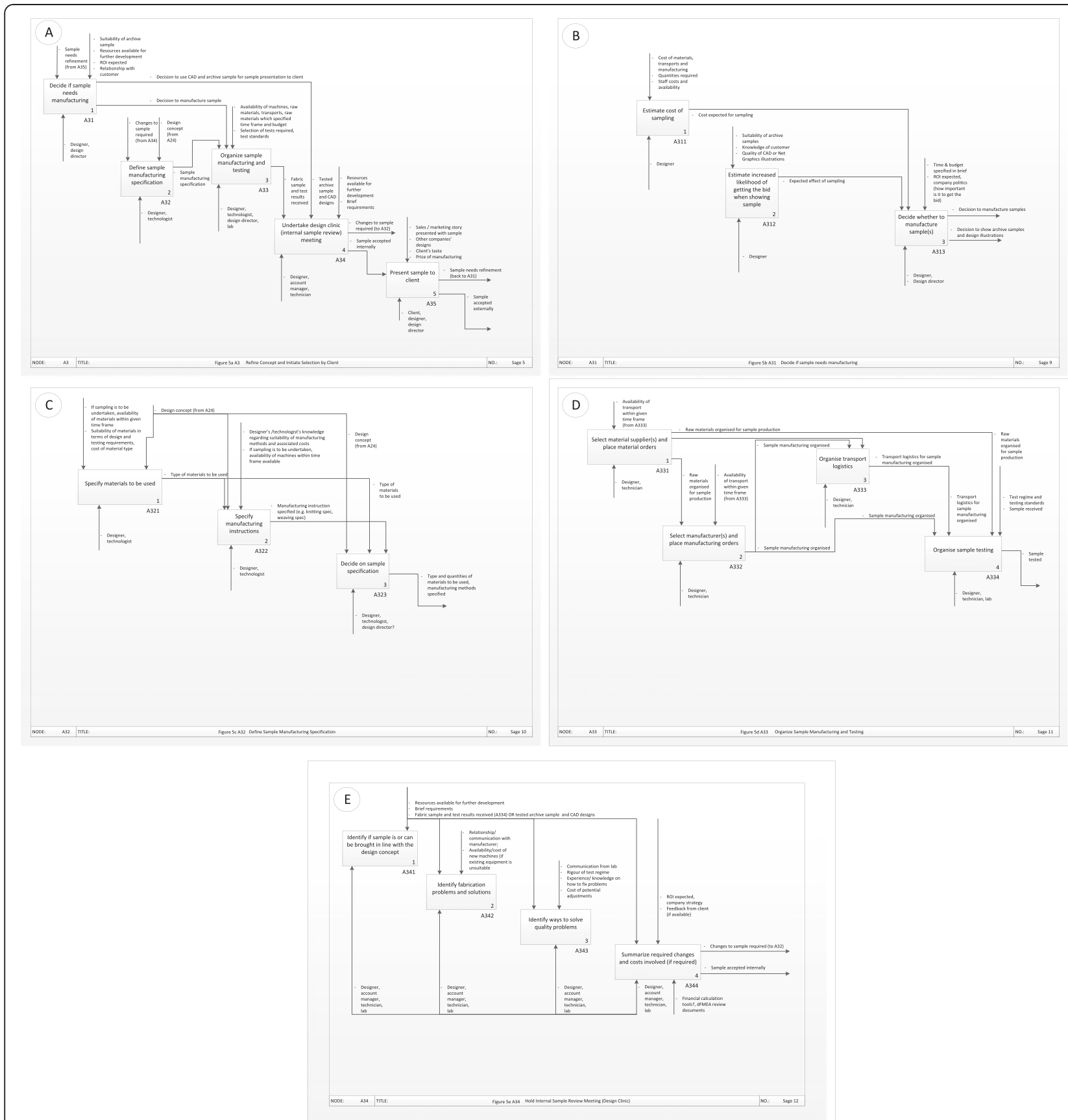

Figure 5 Stages A3 to A34. (A) Stage A3: refine concept and initiate selection by client. (B) Stage A31: initial decision if a sample should be manufactured. (C) Stage A32: defining sample manufacturing specification. (D) Stage A33: organizing sample manufacturing and testing. (E) A34: hold an internal review meeting (design clinic).

As the sample specifications are being defined, there is also the need to organize the logistics for the transportation of the samples and their testing. Samples in automotive textiles are many metres of fabrics, representing bulk and hence the requirement for cost and time efficiencies to be met, as illustrated in Figure 5d.
Once tested, the sample is then examined by the design team for quality of manufacture, standard of testing and financial implications. Any problems are identified with appropriate rectification routes. Samples accepted through this internal design review are presented to the client company (stage A35) who will make the decision to either 


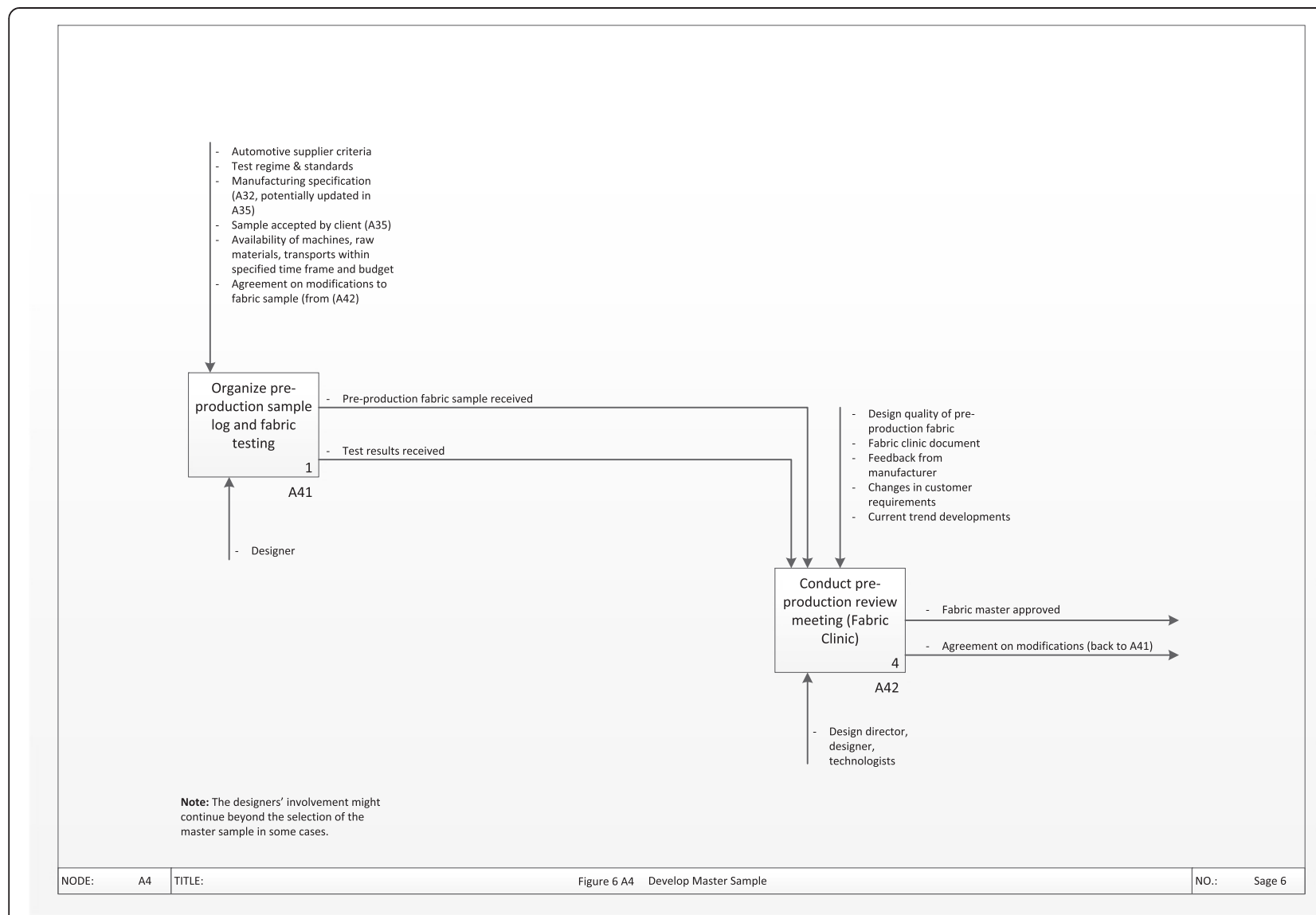

Figure 6 Stage A4: developing the master sample.

review the sample again after specified modifications or to agree that the sample is further developed for manufacture.

\section{Stage A4: develop master sample}

Once the clients have reviewed the samples, decisions are made regarding the merits of developing the sample for production; the first stage of this is the 'master sample'. Approved samples from the client review at stage A35 undergo a second set of testing and colour-tuning (Figure 6); if not approved, design alterations and further sampling will occur. When samples and testing are approved, the design process is finalized, a term described by Sage AI as 'mastering', and this is whereby the whole product is fixed (yarns, design, etc.), contracts are raised, the client firm is financially committed and the design is then assigned to production.

\section{Decision making through the design process regarding recycled textiles}

Sage AI has maintained sustainability as core to their corporate values from Milliken and normally use polyester yarns for their textile products that are visible within the automotive (because it is cost-effective, recyclable and meets the rigorous test requirements). The polyester may be coloured and texturized to a very wide variety of looks and feel that are cost-effective, visually appealing to the customer (the OEM) and pass a number of rigorous tests (such as abrasion and light fastness) so that it will last for up to 10 years.

In line with their sustainability vision, Sage AI also use a percentage of post-industrial recycled yarns and postconsumer (PTC) recycled yarns blended with virgin yarns. Post-industrial recycled yarn is easier for Sage AI to use as properties and provenance are known. Most yarn manufacturing takes place in Asia, but the suppliers of polyester yarns are based in wider locations, e.g. Sage AI (UK) have a supplier in the UK in Nottingham. As the tests that automotive yarns and fabrics have to pass are so rigorous, there are few automotive yarn suppliers. Automotive textile interior fabrics and yarns are therefore sourced from a small pool of yarn suppliers, easing the complexity of the provenance of the yarns.

PTC recycled yarns are made from 100\% plastic bottles, and the benefits of using post-consumer recycled yarns is the reduction in greenhouse gas emissions, the reduced energy consumption compared to making virgin yarns from raw materials and associated landfill charges and land use for storing waste plastic bottles (Collora 
Table 1 Decision-making for using recycled yarn

\begin{tabular}{ll}
\hline Decision & Decision explained \\
\hline Determination of R\&D priorities (A11) & $\begin{array}{l}\text { R\&D priorities (including the lev } \\
\text { of detail at which this is defined), } \\
\text { time and budget allocated to } \\
\text { different open-line activities }\end{array}$ \\
$\begin{array}{ll}\text { Decision whether to work on a } \\
\text { company brief or not (contract } \\
\text { gate opening) (A21a) }\end{array}$ & $\begin{array}{l}\text { Decision whether to open a } \\
\text { contract gate is made; a certain } \\
\text { amount of time and money is } \\
\text { allocated to the project }\end{array}$
\end{tabular}

Decision on which open-line briefs to take forward (internal product development work) (A21b and A21b)

Design idea development - decision which ideas to present (A23)

Design concept selection (A24)

Organization of sample manufacturing and testing (A33)
The decision which open-line brief ideas to work on is taken/ open-line brief ideas are concretized

Design ideas are selected (CAD drawings, samples for presentation)

Design concept selected, incl. CAD drawing, archive sample, initial specification of materials, technologies, manufacturers (A4 selection)

a) Suppliers and manufacturing partners are selected for the product sample (if successful, they are likely to be commissioned with the production of the product once it goes into production as well).

b) Testing is organized ( test regime specified by the respective OEM)
Relevance for environmental sustainability

Level of priority given to EPD in R\&D has direct implications for both innovative and incremental EPD activities (incl. level of detail about specific EPD aspects)

a) The decision whether to work on a brief which requires research into EPD is made, and the time and money allocated to the brief is determined (impacts on the likelihood of the bid being successful).

b) The amount of time/ money allocated to a 'conventional bid' affects the time left for work on specific EPD projects.

c) For any bid, the availability of resources (amount of time/ number of staff members allocated to working on the bid) could influence whether there is scope for exploring EPD as part of the design development

Taking the R\&D priorities into account, the process of narrowing down design ideas requires a decision on whether to work on EPD as part of the R\&D work and what priority they are given over other R\&D ideas - this may be an implicit or explicit process

A decision whether to include design ideas which require sustainable materials and production methods is made.

The design concept selection will largely determine what the actual product will look like and how it will be made, which has direct implications for the environmental impact of its production.

The choice of suppliers and manufacturing partners will affect the environmental impact of the product. The importance of the choice of the manufacturing partners depends on the availability of alternatives and the variability between the manufacturing processes with regards to their environmental impact (e.g. the age of the machines used, materials used, energy sources etc.) - the differences are likely to be greater if the market is global.
Relevance in recycled yarn scenario?

N/A

Yes

N/A

Yes (combined analysis with design concept selection)

Yes (combined analysis with design idea development)

Yes
2012). The benefits are somewhat counterbalanced by the considerations of another supply chain loop; postconsumer yarns are currently 100\% from plastic bottles which require processing into yarns, and there are the collection of plastic bottles, cleaning, transportation and storage of bottles before manufacturing processes, raising issues about transparency within this recycling route (European Environmental Agency 2012).

The use of recycled textiles used in production is a dilemma: the recycled polyester is blended with virgin 
polyester and so the resultant fabric does not look different from the non-recycled fabrics, thus raising questions from OEM customers and final vehicle consumers alike about the validity of the sustainable claims and extra costs. The cost of using recycled yarns appears to be in the processing of the yarn: there is a surcharge/premium in terms of the raw materials which is based on the polyester and not the plastics making it difficult for the OEM customer to understand the costing. The cost implications are, for example, 7\% mark up on fabric that is $40 \%$ recycled and $11 \%$ on fabric that is $100 \%$ recycled; when this is taken back to the yarn, the cost is double or three times that on the normal price of the yarns. According to Ford's research shared with Sage AI, the premiums charged on recycled yarns varied across the world: $10 \%$ to $15 \%$ (USA), $15 \%$ to $20 \%$ (China, India, Brazil), $20 \%$ to $25 \%$ (Europe), $20 \%$ to $30 \%$ (Korea), and $50 \%$ to $100 \%$ (Thailand).

As well as the yarn composition, the application of textiles within the visible areas of automotives presents a problem regarding sustainability. Between seven to nine million vehicles are disposed of annually in the EU; only $75 \%$ of this is recyclable. Textiles form part of the remainder non-recyclable materials (Collora 2012). Textiles from ELV seating make up about $15 \%$ of automotive shredder residue, (ASR - possible to process into vehicular sound proofing insulation and then finally incinerated) (Erth et al. 2008a, 2008b).

Seat covering textile is laminated to impart waterproofness, increased abrasion, stain, flame and UV resistance, retro-reflection properties which the OEM requires testing standards to be achieved. Lamination involves backing onto foam, usually with adhesive. Currently, the most cost-effective lamination process renders textile products to be non-recyclable as lamination involves placing adhesives onto the fabric. It is possible to replace adhesive and foam-based lamination process with three-dimensional knitted or non-woven textiles products stitch-bonded or needle-punched onto the exterior fabric enabling separation of layers and recyclability. It is expensive though and currently only in high-value cars.

As costs appear to be an overriding consideration, we examined the design process to identify where and how decisions were made that were directly related to considerations about using recycled yarns (and by implication the lamination process used). This is presented in Table 1.

From Table 1, it can be seen that there are few, if any, decisions that are under Sage AI's control, save the decision to develop an open-line brief. This is a route that is not now very common for Sage AI as it is risk-laden and demands resources in terms of time and money with no guarantees of developing a sample that wins a contract. However, having developed fabric samples in this way to show at various industry shows did place them as companies who are not only interested in sustainability but also actively seeking solutions.

Decisions around developing sustainable textiles solutions for automotives are through negotiation with the lead firm, the OEM that is seeking to manufacture the model. A study of incorporating sustainability into the supply chain management at Volkswagen (Koplin et al. 2007) noted essentially two forms of environmental supply management: (1) the integration of environmental criteria/standards into product and production-related decisions along the whole supply process ('greening the supply chain') and (2) the optimization of the environmental compatibility of purchased goods ('product-based green supply') (Vermeulen et al. 2011).

In the first route, the supplier is evaluated for their environmental performance; achieving and providing certificates for environmental management systems such as ISO 14001 are regarded as minimum qualification criteria for discussions to commence about supplying a product. Sage AI (UK) has ISO 14001 and will also work with suppliers of their raw materials who have either ISO 14001 or QS-9000 (an automotive standard developed by General Motors, Chrysler and Ford based on ISO 9000). In the second route, all stages of the life cycle are considered from packaging, recycling and disposal. As products are developed in accordance to specifications set by the OEM in the brief, measurable sustainable criteria should help to evaluate the environmental credentials of the product. However, as the case study with Sage AI (UK) attests, the interest in green procurement of sustainable textile products for the automotive sector in Europe has not gained enough ground to warrant all or majority of textile design to be from recycled polyester or the use of non-adhesive lamination. A recent study of sustainable supply chain management within the Indian textile industry not only noted that it was important to identify the most influential drivers within the region as these enablers were observed to be context based (Diabat et al. 2014) but they also observed that within the automotive sector, the customer was a very influential driver to sustainable textile design.

\section{Conclusion}

This paper presents the dichotomies in developing sustainable textile materials for the automotive industry. Recycled and renewable raw materials are two main drivers in the growth of the Mobiletech markets which accounts for about $22 \%$ of the technical textiles base, making it the largest single market and a growth area. There is, however, a disparity in the use of recycled yarns in automotives: in the US market, the Ford Mondeo Fusion Hybrid has been reported as having 100\% recycled yarn whilst the model in the Asian and EU 
markets is reported to have up to $43 \%$ recycled yarn (Green Supply Chain News 2013). According to Messe Frankfurt (2013), the use of textiles within automotive has risen from $20 \mathrm{~kg}$ per car in 2,000 to $26 \mathrm{~kg}$ in 2012 and is set to rise to $35 \mathrm{~kg}$ in 2020 , driven partly by the use of textiles composites and substitution of heavier materials for textiles to cover fuel consumption and $\mathrm{CO} 2$ emissions. Sustainability is important for consumers in the mature automotive markets of the USA and EU; of the top ten decisions driving purchase of automobiles, fuel efficiency was number one and that environmental considerations was number four (KPMG 2013).

As the use of recycled fabrics (and the use of any recyclable textile component) push up the final costs of the car, the consumer has to be interested to buy recycled/sustainable, and this is not easy to predict: there is a large interest in the North Americas, but not so much of a concern within Europe. Research conducted by (European Environmental Agency 2012) identified that in their sample of 1,000 men and women in USA, 70\% of them felt that sustainability was now a mainstream issue for them and that 9 out of 10 of these 'green consumers' wanted to know where recycled materials are used and what recycled fibre brands are used in their cars. The decision to use recycled content within the product therefore rests on cost and questions that need to be addressed by Sage AI (UK) which include:

- Is it a 'deal-breaker', i.e. would the use of recycled textiles parts secure a sale?

- What are the cost implications on the total supply chain?

- Does legislation present any advantages in the use of recycled textiles in production?

Our study demonstrates how the design for automotive textiles is a system, whereby design decisions are a series of negotiations with the client OEM. Our interviews found that although Sage AI headquarters did provide worldwide trends information to all locations, there was some concern regarding consumer knowledge about the EU markets; the implications for Sage AI (UK) are most notable in their ability to persuade the client to work with them towards the most sustainable textiles solutions, rather than achieving lowest cost. With reference to Meadows (1997) and her nine interventions for influencing and changing systems, the automotive sector already have governmental policy drivers and material stocks and flows in that the technology is currently available for recyclable and sustainable textiles to be developed for the automotive sector. Given the strength of consumer interest in the US for sustainable textiles within the vehicle, it would be interesting to research how the US consumer became engaged with this. Some of the questions raised from this case study are as follows:

- How are the costs of recycled yarns determined?

- How can equality in costs of recycled/virgin yarns be achieved?

- How can/should the sustainability message for recycled textiles be delivered?

- What new technologies may be developed to ensure that end-of-life considerations can be taken into account when developing laminated textiles for automotive interiors?

\section{Competing interests}

The authors declare that they have no competing interests.

Received: 20 December 2014 Accepted: 17 March 2015 Published online: 07 August 2015

\section{References}

Charnley, F., Lemon, M., Evans, S. (2011), Exploring the process of whole system design, Design Studies 32 (2011) 156-179, doi:10.1016/j.destud.2010.08.002 156, Elsevier Ltd.

Collora, J. (2012) Recycling empty PET bottles, Bottled Water Reporter, December 2011-January 2012, pp8-14, International Bottled Water Association http:// www.nxtbook.com/ygsreprints/IBWA/g23199_IBWA_DecJan12/\#/10

Diabat, A, Kannan, D, \& Mathiyazhagan, K. (2014). Analysis of enablers for implementation of sustainable supply chain management - a textile case. Journal of Cleaner Production, 83(2014), 391-403.

EEA (European Environmental Agency) (2012) Movements of waste across the EU's internal and external borders, EEA, ISBN 978-92-9213-337-5

Erth, H, Gulich, B, \& STFI. (2008a). Three-dimensional textiles and nonwovens for polyurethane foam substitution in car seats. In R Shishoo (Ed.), Textile advances in the automotive industry (pp. 140-149). Cambridge: Woodhead Publishers Ltd.

Erth, H, Gulich, B, \& STFI. (2008b). Three-dimensional textiles and nonwovens for polyurethane foam substitution in car seats. In R Shishoo (Ed.), Textile advances in the automotive industry (p. 147). Cambridge: Woodhead Publishers Ltd.

EURAPA. (2010). Summaries of EU legislation: end-of-life vehicles. Retrieved 07-11-2011, from http://europa.eu/legislation_summaries/environment/waste_management/ 121225 en.htm

Green Supply Chain News (2013) Ford Motor Company keeps pushing the green envelop as it continues to expand use of recycled materials inside its cars, http://www.thegreensupplychain.com/news/13-05-20-1.php?cid=7093

Hernandez-Matias, JC, Vizan, A, Perez-Garcia, J, \& Rios, J. (2008). An integrated modelling framework to support manufacturing system diagnosis for continuous improvement. Robotics and Computer-Integrated Manufacturing, 24(2), 187-199. http://dx.doi.org/10.1016/j.rcim.2006.10.003.

Hirao, M., Sugiyama, H., Fischer, U., \& Hungerbühler, K. (2008). IDEFO activity modeling for integrated process design considering environmental, health and safety (EHS) aspects. In B. Bertrand \& J. Xavier (Eds.), Computer Aided Chemical Engineering (Vol. Volume 25, pp. 1065-1070): Elsevier.

Kikuchi, Y., \& Hirao, M. (2009). Activity and information modeling of comprehensive assessment for sustainable process design. In J. Jacek \& T. Jan (Eds.), Computer Aided Chemical Engineering (Vol. Volume 26, pp. 1123-1128): Amsterdam, London:Elsevier.

Kikuchi, Y., Papadokonstantakis, S., Banimostafa, A., Sugiyama, H., Hungerbuhler, K., \& Hirao, M. (2012). Analysis and modeling of information required for process assessment on environment, health, and safety by IDEFO and UML. In A. K. Iftekhar \& S. Rajagopalan (Eds.), Computer Aided Chemical Engineering (Vol. Volume 31, pp. 1392-1396): Amsterdam, London:Elsevier.

Knowledge Based Systems, I., (2010). IFEDO - function modelling method, Retrieved 17/09/2012, 2012, from http://www.idef.com/IDEF0.htm 
Koplin, J, Seuring, S, \& Mesterharm, M. (2007). Incorporating sustainability into supply management in the automotive industry - the case of the Volkswagen AG. Journal of Cleaner Production, 15, 1053-1062.

KPMG. (2013). KPMG's global automotive executive survey 2013. https:/www.kpmg.com/ $\mathrm{KZ} / \mathrm{ru} /$ IssuesAndlnsights/ArticlesAndPublications/Documents/KPMGs-GlobalAutomotive-Executive-Survey-2013.pdf

Meadows, D., H, (1997) Places to intervene in a system, Whole Earth, Winter, http://www.wholeearth.com/issue/2091/

Messe Frankfurt (2013) Sustainability Recycling concepts and natural fibres in motor vehicles, http://www.messefrankfurt.com/frankfurt/en/media/ textiletechnologies/techtextil/frankfurt/texte/autositze-und-dachhimmel-ausholz-flachs-mais-und-recycel-tem-.html

Mingers, J, \& White, L. (2010). A review of the recent contribution of systems thinking to operational research and management science. European Journal of Operational Research, 207, 1161. Elsevier.

National Institute of Standards and Technology. (1993). Draft federal information processing standards publication 183 - standard for integration definition for function modeling (IDEFO).

Normand, X. (2008). In R Shishoo (Ed.), Textile advances in the automotive industry (pp. 86-109). Cambridge: Woodhead Publishing Ltd. pp. 87-88.

Powell, NB. (2006). New textile product development: processes, practices, and products. The Journal of The Textile Institute, 97(2), 155-166.

Powell, NB. (2008a). Design of automotive interior textiles. In R Shishoo (Ed.), Textile advances in the automotive industry (pp. 113-139). Cambridge: Woodhead Publsihing Ltd.

Powell, NB, Handfield, R, \& Barnhardt, R. (2008b). Mapping the automotive textile supply chain. In R Shishoo (Ed.), Textile advances in the automotive industry (pp. 17-42). Cambridge: Woodhead Publishing Ltd.

Rashid, MM, \& Ismail, H. (2007). Generic tool for measuring the reliability of product development processes. Journal of Modelling in Management, 2(1), 71-93.

Shishoo, R. (2008). Textile advances in the automotive industry: Woodhead Publishing

Sugiyama, H, Hirao, M, Fischer, U, Hungerb, U, \& Hler, K. (2008). Activity modeling for integrating environmental, health and safety (EHS) consideration as a new element in industrial chemical process design. Journal of Chemical Engineering of Japan, 41(9), 884-897.

Taylor, I. (2012). Interview with design and product development director at Sage Al, December 2011.

Vermeulen, I, Van Caneghem, J, Block, C, Baeyens, J, \& Vandecasteele, C. (2011). Automotive shredder residue (ASR): reviewing its production from end-of-life vehicles (ELVs) and its recycling, energy or chemicals' valorisation. Journal of Hazardous Materials, 190(1-3), 8-27.

Yin (2009), Case study research: design and methods, p. 13, California:Sage

Yu, B, \& Wright, DT. (1997). Software tools supporting business process analysis and modelling. Business Process Management Journal, 3(2), 133-150.

\section{Submit your manuscript to a SpringerOpen ${ }^{\circ}$ journal and benefit from:}

- Convenient online submission

- Rigorous peer review

- Immediate publication on acceptance

- Open access: articles freely available online

- High visibility within the field

- Retaining the copyright to your article

Submit your next manuscript at $\gg$ springeropen.com 